\title{
PENGARUH TEMPERATUR DAN KONSENTRASI KATALIS PADA CRACKING CANGKANG SAWIT MENJADI CRUDE BIO-FUEL
}

\author{
Sunarno, Silvia R.Y, dan Syaiful Bahri \\ Jurusan Teknik Kimia Fakultas Teknik Universitas Riau \\ Kampus Binawidya Km 12,5 Panam Pekanbaru \\ narnounri@yahoo.com
}

\begin{abstract}
One of solid waste that produced by palm industry is palm oil shell. This waste abundant in Riau about 700.5 ton/day. The shell compositions are cellulosa, hemicellulosa, and lignine. That compounds can be cracked into crude biofuel in slurry reactor with NiMo/ZSM-5 catalyst. The objective of research to study the influence of cracking temperature $\left(300,310,320,330{ }^{\circ} \mathrm{C}\right)$ and concentration of catalyst $(0.5 ; 1.5 ; 2.5 ; 3.5 \%)$ to yield of crude biofuel and to determine physical and chemical properties. Cracking process used 50 gram palm oil shell size $-40+60$ mesh, $500 \mathrm{~mL}$ silinap and rotation speed of mixing $300 \mathrm{rpm}$. The maximum yield was obtained $68.6 \%$ at temperature $330{ }^{\circ} \mathrm{C}$ and catalyst concentration NiMo/ZSM-5 2.5\%. The physical properties of crude biofuel were calorimetric value $(43.84 \mathrm{MJ} / \mathrm{kg})$, density $(1.01 \mathrm{~g} / \mathrm{mL})$, viscocity $(13.27 \mathrm{cSt})$, acid number $\left(76.11 \mathrm{~g} \mathrm{NaOH} / \mathrm{g}\right.$ sample) and flash point $\left(64{ }^{\circ} \mathrm{C}\right)$. The GC-MS analysis result indicated dominant compounds in crude biofuel were acetic acid (33.94\%), phenol (31.71\%), furancarboxaldehide (7.78\%) and methanol (4.93\%).
\end{abstract}

Key words : Catalyst, crude biofuel, palm oil shell

\section{DAFTAR PUSTAKA}

1. BPS Provinsi Riau, 2011, Riau dalam Angka 2010, http://riau.bps.go.id/ publikasi-online.html, 19/05/2011.

2. Departemen Pertanian Direktorat Jenderal Perkebunan, 2011, Stastistik Perkebunan Indonesia 2009-2011, http://regionalinvestment.com, 27/11/2011.

3. I. Febijanto, Kajian teknis dan keekonomian pembangkit listrik tenaga biomassa sawit, Pusat Teknologi Pengembangan Sumber Daya Energi, Jakarta, 2011.

4. A. G. Gayubo, A. T. Aguayo, Atutxa, Alaitz, Valle, Beatriz, Bilbao, and Javier, Undesired components in the transformation of biomass pyrolysis oil into hydrocarbons on an HZSM-5 zeolite catalyst, Ind Eng Chem., 80: 1244-1251, (2005).

5. A. Awaluddin, Proses pencairan langsung biomassa menjadi crude biofuel dengan menggunakan thermo-oil, I-MHERE Project., HEI-IU Universitas Riau, (2007)

6. S. S. Abdullah, S. Yusup, M. M. Ahmad, A. Ramli, and L. Ismail, Thermogravimetry study on pyrolysis of various lignocellulosic biomass for potential hydrogen production. International Journal of Chemical and Biological Engineering., 3(3): 137-141, (2010).

7. M. Irfan, Pyrolysis tandan kosong sawit dengan katalis CoMo/ZSM-5 Menjadi Bio-oil, Skripsi, 2010, Universitas Riau.

8. Setiadi, Y. Darmawan, dan R. M. Fitria, Pemanfaatan zeolit alam sebagai komponen penyangga katalis untuk reaksi hidrogenasi $\mathrm{CO}_{2} \&$ perengkahan minyak sawit, Prosiding seminar nasional zeolit V, Ikatan Zeolit Indonesia(IZI), 2006, Bandar Lampung.

9. Biomass Technology Group, 2003, Biooil Applications. http://www.btgworld .com/technologies/b iooilapplication.hm-tl. 16/15/2011. 
10. Y. S. Indra, Pembuatan dan karakterisasi katalis Ni-Mo/NZA untuk proses catalytic cracking tandan kosong sawit menjadi bahan bakar cair, Laporan Penelitian, Jurusan Teknik Kimia Fakultas Teknik, 2010, Universitas Riau, Pekanbaru.
11. Purwanto, Widodo, A. O. Ningrum, dan R. Muthia, Pengembangan produksi bio-oil dari limbah kelapa sawit dengan metode fast pyrolysis, Prosiding Seminar Nasional Teknik Kimia Teknologi Oleo dan Petro Kimia, 2011, Riau. 